\title{
Antioxidant and antibacterial activities of exopolysaccharides from Bifidobacterium bifidum WBIN03 and Lactobacillus plantarum R315
}

\author{
Shengjie Li, ${ }^{*} \dagger$ Renhui Huang, ${ }^{*}$ Nagendra P. Shah, $\ddagger^{1}$ Xueying Tao, ${ }^{\dagger} \dagger$ Yonghua Xiong, ${ }^{*} \dagger$ and Hua Wei ${ }^{*} \dagger^{1}$ \\ *State Key Laboratory of Food Science and Technology, Nanchang University, Nanchang 330047, P. R. China \\ †Jiangxi-OAI Joint Research Institute, Nanchang University, Nanchang 330047, P. R. China \\ †Food and Nutritional Science, School of Biological Science, The University of Hong Kong, Pokfulam Road, Hong Kong, China
}

\section{ABSTRACT}

The objective of this study was to investigate the antioxidant and antibacterial activities of exopolysaccharide (EPS) from Bifidobacterium bifidum WBIN03 (B-EPS) and Lactobacillus plantarum R315 (L-EPS). The 1,1-diphenyl-2-picrylhydrazyl (DPPH)-radical scavenging, hydroxyl radical-scavenging, and superoxide radical-scavenging abilities were measured to evaluate antioxidant activity. Inhibition of erythrocyte hemolysis and lipid peroxidation was also measured. Both B-EPS and L-EPS had strong scavenging ability against DPPH and superoxide radicals at high concentration. The inhibitory effect of B-EPS on erythrocyte hemolysis was stronger than that of L-EPS in a concentration range from 0.30 to $1.00 \mathrm{mg} / \mathrm{mL}$, whereas the hydroxyl scavenging ability of L-EPS $(39.15 \pm 0.58 \%)$ was significantly higher than that of $0.15 \mathrm{mg} / \mathrm{mL}$ ascorbic acid $(24.33 \pm 1.17 \%)$ and B-EPS $(17.89 \pm 3.30 \%)$ at $0.10 \mathrm{mg} / \mathrm{mL}$. The inhibition of lipid peroxidation of $0.50 \mathrm{mg} / \mathrm{mL}$ B-EPS and L-EPS was $13.48 \pm 1.74 \%$ and $12.43 \pm 0.51 \%$, respectively, values lower than that of ascorbic acid at the same concentration (23.20 \pm $1.41 \%)$. Furthermore, all these abilities were enhanced in a concentration-dependent manner. Agar diffusion assay showed that both EPS exhibited antibacterial activities against tested pathogens such as Cronobacter sakazakii, Escherichia coli, Listeria monocytogenes, Staphyloccocus aureus, Candida albicans, Bacillus cereus, Salmonella typhimurium, and Shigella sonnei at 300 $\mu \mathrm{g} / \mathrm{mL}$. In conclusion, both EPS have antimicrobial and antioxidant activities and could have applications in the food industry.

Key words: exopolysaccharide, antioxidative and antibacterial activity, Lactobacillus plantarum, Bifidobacterium bifidum

Received January 7, 2014.

Accepted July 22, 2014.

${ }^{1}$ Corresponding authors: npshah@hku.hk and weihua114@live.cn

\section{INTRODUCTION}

Reactive oxygen species such as superoxide, hydroxyl radical, and hydrogen peroxide are highly reactive species, and a major cause of ill effects in humans, including cancer, atherosclerosis, rheumatoid arthritis, and neurodegenerative diseases. These conditions are caused by the damaging effects of reactive oxygen species on biological molecules such as DNA, lipids, and proteins (Ames et al., 1993; Aruoma, 1998). Concern regarding the safety and toxicity of synthetic antioxidants has increased; hence, researchers are challenged to find natural antioxidants that do not adversely affect human health (Valentão et al., 2002; Soubra et al., 2007). In recent years, polysaccharides from yeast, fungi, and medicinal plants have been reported to possess antioxidant activities and could be used as natural antioxidants (Kogan et al., 2008; Yin et al., 2010).

Food poisoning and food spoilage are the most important global issues for the public (Gram et al., 2002), especially in developing countries. Many pathogenic microorganisms, such as Staphylococcus aureus, Bacillus subtilis, Listeria monocytogenes, Escherichia coli O157:H7, and Candida spp. have been identified as causative agents for foodborne diseases (Sokmen et al., 2004; He et al., 2010). Emergence of multidrugresistant bacteria has challenged the search for natural antimicrobial substances to prevent food poisoning and spoilage. Recently, many antimicrobial compounds produced by lactic acid bacteria (LAB), including bacteriocins, diacetyl, organic acids, carbon dioxide, and some other low-molecular-weight substances, such as reuterin, reutericyclin, and antifungal peptides, have been studied (Nes et al., 2011). However, few studies have focused on antimicrobial and antioxidant activities of exopolysaccharides (EPS) produced by LAB (He et al., 2010; Wu et al., 2010).

Exopolysaccharides, long-chain polysaccharides produced by LAB that are secreted into the growth medium during the metabolic process, have attracted recent attention, mainly due to their potential healthpromoting functions (Ruas-Madiedo et al., 2002; Badel et al., 2011; Hidalgo-Cantabrana et al., 2012). Interest 
Table 1. Exopolysaccharide (EPS) production by Bifidobacterium, Lactobacillus, Lactococcus and their growth ability (optical density, OD, at $600 \mathrm{~nm}$ ) in de Man, Rogosa, and Sharpe (MRS) or MRS with L-cysteine medium

\begin{tabular}{llcc}
\hline Species/strain & Origin & $\begin{array}{c}\text { Growth OD } \\
\text { at } 24 \mathrm{~h}\end{array}$ & $\begin{array}{c}\text { EPS production } \\
\text { (mg/L) }\end{array}$ \\
\hline Bifidobacterium bifidum WBIN03 & Human feces & $1.82 \pm 0.01$ & $241.20 \pm 1.55$ \\
Lactococcus lactis WLLA11 & Human feces & $1.54 \pm 0.04^{\mathrm{c}}$ & $200.72 \pm 5.43^{\mathrm{c}}$ \\
Lactobacillus acidophilus WLAC12 & Human feces & $1.55 \pm 0.07^{\mathrm{c}}$ & $210.94 \pm 3.02^{\text {cd }}$ \\
Lactobacillus paracasei WLPA13 & Human feces & $1.59 \pm 0.14^{\mathrm{c}}$ & $243.44 \pm 5.56^{\mathrm{ef}}$ \\
Lactobacillus johnsoni WLJO14 & Human feces & $1.59 \pm 0.06^{\mathrm{c}}$ & $243.85 \pm 3.21^{\mathrm{ef}}$ \\
Lactobacillus plantarum R315 & Breast milk & $1.85 \pm 0.02^{\mathrm{d}}$ & $290.17 \pm 19.72^{\mathrm{g}}$ \\
Lactobacillus plantarum WCFS1 & Sourdough & $1.66 \pm 0.03^{\mathrm{c}}$ & $174.83 \pm 10.42^{\mathrm{b}}$ \\
Lactobacillus delbrueckii L001 & ATCC 9649 & $1.74 \pm 0.06^{\mathrm{cd}}$ & $232.55 \pm 8.77^{\mathrm{de}}$ \\
Lactobacillus rhamnosus GG L002 & ATCC 7469 & $1.72 \pm 0.04^{\mathrm{cd}}$ & $218.94 \pm 8.99^{\mathrm{cd}}$ \\
Lactobacillus fermentum S001 & Sourdough & $1.52 \pm 0.03^{\mathrm{c}}$ & $214.48 \pm 3.39^{\text {cd }}$ \\
Lactobacillus casei V003 & Villi & $1.60 \pm 0.11^{\mathrm{c}}$ & $255.62 \pm 9.21^{\mathrm{ef}}$ \\
Lactobacillus johnsonii T003 & Pig feces & $1.55 \pm 0.031^{\mathrm{c}}$ & $263.03 \pm 7.89^{\mathrm{f}}$ \\
Lactobacillus gasseri PBZF04 & Pig feces & $1.52 \pm 0.04^{\mathrm{c}}$ & $255.31 \pm 6.32^{\mathrm{ef}}$ \\
Lactobacillus vaginalis PBZB08 & Pig feces & $0.85 \pm 0.08^{\mathrm{b}}$ & $260.09 \pm 19.23^{\mathrm{f}}$ \\
Lactobacillus plantarum PFK03 & Villi & $0.53 \pm 0.16^{\mathrm{a}}$ & $45.49 \pm 12.46^{\mathrm{a}}$ \\
\hline
\end{tabular}

${ }^{a-g}$ Data with different letters within a column are significantly different at $P<0.05$.

${ }^{1}$ Each value in the table is mean $\pm \mathrm{SD}$ of 3 trials.

${ }^{2}$ The results for B. bifidum have been published previously (Li et al., 2014).

has grown in exploiting the EPS-producing LAB for their possible biological activities and important industrial applications. Recently, many new LAB strains have been found to have antibacterial or antioxidant activities (Shen et al., 2011; Li et al., 2012; Serafini et al., 2013). However, these studies were performed without identifying the specific compounds that contributed to these activities. Similarly, only a few studies have focused on the antioxidative and antibacterial effects of EPS produced by LAB (Xu et al., 2011a; Li et al., 2013).

In our previous study, we found that EPS from $B i$ fidobacterium bifidum WBIN03 exhibited significant beneficial effects on gut microbiota (Li et al., 2014). We also observed that Lactobacillus plantarum R315 produced EPS more efficiently. In the present study, we examined antioxidant and antibacterial activities of EPS from B. bifidum WBIN03 and Lb. plantarum R315.

\section{MATERIALS AND METHODS}

\section{Microorganisms and Culture Conditions}

Twenty-three probiotic organisms used in this study were isolated from various sources and identified (Table 1). Lactobacillus and Lactococcus were cultured in de Man, Rogosa, and Sharpe broth (MRS; Beijing Solarbio Science and Technology Co. Ltd., Beijing, China) medium and Bifidobacterium was cultured in MRS medium supplemented with L-cysteine at $0.5 \mathrm{~g} / \mathrm{L}$ (MRSc) at $37^{\circ} \mathrm{C}$ under anaerobic condition. These strains were selected to evaluate their growth ability and EPS yield.

Eight pathogens-Candida albicans Z1, Cronobacter sakazakii ATCC29544, Escherichia coli O157:H7,
Listeria monocytogenes CMCC54007, Staphyloccocus aureus CMCC26003, Bacillus cereus ATCC14579, Salmonella typhimurium ATCC13311, and Shigella sonnei ATCC25931 - were used as indicator organisms. These bacteria were cultured in Luria-Bertani medium at $37^{\circ} \mathrm{C}$ in a shaker incubator overnight except for $\mathrm{Ca}$. albicans Z1, which was cultured in yeast extract-peptonedextrose medium at $30^{\circ} \mathrm{C}$ for $36 \mathrm{~h}$.

1,1-Diphenyl-2-picrylhydrazyl (DPPH) was purchased from Sigma Chemical Co. (St Louis, MO), and all other reagents used were analytical grade and purchased from Shanghai Chemicals and Reagents Co. (Shanghai, China).

\section{Analysis of Bacterial Growth and EPS Production}

Cultivation of each strain for EPS production and bacterial growth was performed as batch cultures in $100 \mathrm{~mL}$ of MRS or MRSc broth at $37^{\circ} \mathrm{C}$ in $250-\mathrm{mL}$ Erlenmeyer flasks. Samples ( $5 \mathrm{~mL}$ of each strain) were withdrawn after $24 \mathrm{~h}$ of incubation to measuring absorbance at $600 \mathrm{~nm}$. Exopolysaccharide was isolated from samples according to the method described below.

\section{Extraction, Purification, and Detection of EPS}

The methods used for extraction, purification, and detection of EPS are based on the method of Chen et al. (2011). Briefly, each strain was separately inoculated (1\%) in $500 \mathrm{~mL}$ of MRS or MRSc and incubated at $37^{\circ} \mathrm{C}$ under anaerobic conditions for $24 \mathrm{~h}$ without $\mathrm{pH}$ control. Cells were removed after centrifugation $(4,000$ $\times g, 10 \mathrm{~min}, 24^{\circ} \mathrm{C}$ ), and the supernatant was precipitated with equal volume of ethanol overnight at $4^{\circ} \mathrm{C}$ fol- 
lowed by centrifugation $\left(8,000 \times g, 20 \mathrm{~min}, 4^{\circ} \mathrm{C}\right)$. The precipitates were collected and dissolved in distilled water. Proteins were removed with one-quarter of the volume Sevage solution (chloroform: $n$-butanol; $4: 1$ ) followed by centrifugation $\left(8,000 \times \mathrm{g}, 10 \mathrm{~min}, 24^{\circ} \mathrm{C}\right)$, and finally the collected EPS was dialyzed against distilled water for $1 \mathrm{~d}$ at $4^{\circ} \mathrm{C}$. The uniformity of the EPS was examined by gel filtration using a column $(75 \times 1.5 \mathrm{~cm})$ of Bio-Gel P-30 polyacrylamide gel (Bio-Rad, Hercules, CA; exclusion limit: 35,000 Da). The concentration of EPS was determined by measuring the glucose content using the phenol-sulfuric acid assay method (Dubois et al., 1956).

\section{Antioxidant Activity of EPS by Scavenging DPPH Free Radical}

The DPPH free radical-scavenging activities of EPS were determined according to the method of Yin et al. (2010). Briefly, $0.2 \mathrm{mM}$ ethanolic DPPH (Sigma Chemical Co.) radical solution was prepared. An aliquot (1.0 $\mathrm{mL}$ ) of each sample (with appropriate dilution) was added to $1.0 \mathrm{~mL}$ of ethanolic DPPH radical solution. Discoloration was measured at $517 \mathrm{~nm}$ in triplicate after incubation in the dark for $30 \mathrm{~min}$. Ascorbic acid was used as the positive control. The percentage of scavenged DPPH radical was calculated using the following formula:

$$
\begin{gathered}
\text { Scavenging ability }(\%)= \\
{\left[1-\left(\mathrm{A}_{\text {sample }}-\mathrm{A}_{\text {blank }}\right) / \mathrm{A}_{\text {control }}\right] \times 100,}
\end{gathered}
$$

where $A_{\text {sample }}$ is the absorbance of the sample, $A_{\text {blank }}$ is the absorbance of the blank, and $\mathrm{A}_{\text {control }}$ is the absorbance of the control. Ethanol $(1.0 \mathrm{~mL})$ plus sample solution with different dilutions $(1.0 \mathrm{~mL})$ were used as blanks and DPPH radical-ethanol solution $(1.0 \mathrm{~mL})$ plus ethanol $(1.0 \mathrm{~mL})$ as a negative control.

\section{Antioxidant Activity of EPS by Scavenging Hydroxyl Radical}

The test was carried out according to Yin et al. (2010), with a slight modification. Briefly, $2.0 \mathrm{~mL}$ of PBS (20 mM, pH 7.4), $1.0 \mathrm{~mL}$ of 1,10-phenanthroline solution $(2.5 \mathrm{mM}), 1.0 \mathrm{~mL}$ of $\mathrm{FeSO}_{4}$ solution $(2.5 \mathrm{mM})$, and $1 \mathrm{~mL}$ of $\mathrm{H}_{2} \mathrm{O}_{2}(20 \mathrm{mM})$ were added successively in a tube and mixed thoroughly. Then, $1 \mathrm{~mL}$ of EPS aliquot with various concentrations was added in the mixture and incubated at $37^{\circ} \mathrm{C}$ for $1 \mathrm{~h}$. The absorbance was measured at $536 \mathrm{~nm}$ immediately and hydroxyl radical scavenging activity was expressed as

$$
\begin{gathered}
\text { Scavenging activity }(\%)= \\
{\left[\left(\mathrm{A}_{\mathrm{S}}-\mathrm{A}_{\mathrm{C}}\right) /\left(\mathrm{A}_{\mathrm{O}}-\mathrm{A}_{\mathrm{C}}\right)\right] \times 100,}
\end{gathered}
$$

where $A_{S}$ is the absorbance in the presence of the sample, $A_{C}$ is the absorbance of the control in the absence of the sample, and $\mathrm{A}_{O}$ is the absorbance without both sample and $\mathrm{H}_{2} \mathrm{O}_{2}$.

\section{Antioxidant Activity of EPS by Scavenging Superoxide Radical}

This assay was performed according to Zhang et al. (2011), with minor modifications. An aliquot of $2.0 \mathrm{~mL}$ of Tris-HCl buffer ( $\mathrm{pH} 8.0,150 \mathrm{mM}$ ) was mixed with $1.0 \mathrm{~mL}$ of 1,2,3-phentriol $(1.50 \mathrm{~m} M$, dissolved with 10 $\mathrm{m} M \mathrm{HCl}$ ) and $0.5 \mathrm{~mL}$ of sample solutions with different concentrations. After thorough mixing, the mixture was incubated at room temperature for $30 \mathrm{~min}$. The absorbance of the mixture was measured at $325 \mathrm{~nm}$ and superoxide radicals scavenging generated by 1,2,3-phentriol autoxidation was calculated as follows:

$$
\begin{gathered}
\text { Scavenging effect }(\%)= \\
{\left[1-\left(\mathrm{A}_{11}-\mathrm{A}_{10}\right) /\left(\mathrm{A}_{01}-\mathrm{A}_{00}\right)\right] \times 100,}
\end{gathered}
$$

where $A_{00}$ is the absorbance of the sample in the absence of EPS and 1,2,3-phentriol, $\mathrm{A}_{01}$ contained 1,2,3-phentriol but no EPS, $\mathrm{A}_{10}$ contained EPS but no 1,2,3-phentriol, and $\mathrm{A}_{11}$ contained EPS and 1,2,3-phentriol.

\section{Inhibition of Lipid Peroxidation}

This assay was carried out according to the method of Yin et al. (2010). The yolk suspension was prepared according to $\mathrm{Xu}$ et al. (2011b). One milliliter of yolk suspension was mixed with $1.0 \mathrm{~mL}$ of different concentrations of sample, $0.4 \mathrm{~mL}$ of $25 \mathrm{mM} \mathrm{FeSO}_{4}$, and $2.6 \mathrm{~mL}$ of PBS followed by incubation under shaking at $37^{\circ} \mathrm{C}$ for $15 \mathrm{~min}$. The reaction was stopped by adding $1.0 \mathrm{~mL}$ of $20 \%$ TCA and heating at $100^{\circ} \mathrm{C}$ for 15 min with $2 \mathrm{~mL}$ of $0.8 \%$ thiobarbituric acid. After centrifugation $(3,000$ $\left.\times g, 10 \mathrm{~min}, 24^{\circ} \mathrm{C}\right)$ to remove precipitated proteins, the absorbance was measured at $532 \mathrm{~nm}$. The inhibition capability of lipid peroxidation was calculated as follows:

$$
\text { Inhibition effect }(\%)=\left(\mathrm{A}_{\mathrm{C}}-\mathrm{A}_{\mathrm{S}}\right) / \mathrm{A}_{\mathrm{C}} \times 100 \text {, }
$$

where $A_{C}$ is the absorbance of the control and $A_{S}$ is the absorbance in the presence of samples.

\section{Inhibition of Erythrocyte Hemolysis}

The protocol for carrying out animal experiments was approved by Nanchang University Animal Ethics Com- 
mittee and all the ethical requirements to conduct the experiment were met. All procedures were conducted in compliance with protocols provided and approved by the Animal Care Review Committee (approval number 0064257) of Nanchang University (Jiangxi, China).

Blood samples were collected from Kunming mice (BW of $25.0 \pm 2.0 \mathrm{~g}$ ) by plucking the eyeball (retroorbital blood collection), and then, a $1.25 \%$ erythrocyte suspension was obtained according to Saengkhae et al. (2007).

The inhibition of mice erythrocyte hemolysis by EPS was evaluated according to the procedures of $\mathrm{Xu}$ et al. (2011b) with a slight modification. Briefly, different concentrations of samples were incubated at $37^{\circ} \mathrm{C}$ for 30 min with $2.0 \mathrm{~mL}$ of erythrocyte suspension and $1.0 \mathrm{~mL}$ of $\mathrm{H}_{2} \mathrm{O}_{2}(2.5 \mathrm{mM})$. Then, the mixture was incubated in a $0^{\circ} \mathrm{C}$ ice water bath immediately to terminate the reaction and centrifuged at $3,000 \times g$ for $10 \mathrm{~min}$ at $24^{\circ} \mathrm{C}$. The absorbance was measured at $540 \mathrm{~nm}$. In the control testing, $\mathrm{H}_{2} \mathrm{O}_{2}$ and the sample were substituted with Tris buffer. In the $\mathrm{H}_{2} \mathrm{O}_{2}$ control, the sample was substituted with Tris buffer.

The extent of hemolysis of the erythrocyte was calculated as follows:

$$
\text { Extent of hemolysis }(\%)=\mathrm{A}_{\text {sample }} / \mathrm{A}_{\mathrm{H}_{2} \mathrm{O}_{2}} \times 100
$$

where $A_{\text {sample }}$ is the absorbance of the sample and $\mathrm{A}_{\mathrm{H}_{2} \mathrm{O}_{2}}$ is the absorbance of the $\mathrm{H}_{2} \mathrm{O}_{2}$ control.

The inhibition rate of the protein was calculated by the following equation:

Inhibition rate $(\%)=\left(\mathrm{A}_{\mathrm{H}_{2} \mathrm{O}_{2}}-\mathrm{A}_{\text {sample }}\right) /\left(\mathrm{A}_{\mathrm{H}_{2} \mathrm{O}_{2}}-\mathrm{A}_{\text {normal }}\right) \times 100$,

where $A_{\text {normal }}$ is the absorbance of the control and other terms are as defined previously.

\section{Antimicrobial Activities of EPS}

The antibacterial activity of EPS was investigated by agar diffusion assay as described by Chen et al. (2014) with a slight modification. Overnight incubation cultures of the indicator microorganisms were diluted to $10^{6}$ to $10^{7} \mathrm{cfu} / \mathrm{mL}$ and then spread on $10 \mathrm{~mL}$ of Luria-Bertani or yeast extract-peptone-dextrose agar in a Petri dish. Then, $200 \mu \mathrm{L}$ of EPS $(300 \mu \mathrm{g} / \mathrm{mL})$ was added into an Oxford cup (a stainless cylinder of o.d. $7.8 \pm 0.1 \mathrm{~mm}$, i.d. $6.0 \pm 0.1 \mathrm{~mm}$, and height $10.0 \pm 0.1$ $\mathrm{mm}$ ), which was placed on the surface of the agar. The incubation temperature was as described in the section "Microorganisms and Culture Conditions." The size of the clear zone around the cup (including that of the Oxford cup, $7.8 \mathrm{~mm}$ ) was measured. The experiment was performed in triplicate, and ampicillin (100 $\mu \mathrm{g} /$ $\mathrm{mL}$ ) was used as a positive control.

\section{Statistical Analysis}

Data were statistically analyzed using the one-way ANOVA procedure of SPSS (version 13.0; IBM Corp., Chicago, IL) and expressed as mean $\pm \mathrm{SD}$. All these experiments were performed in triplicate and within each replication; analyses were carried out in duplicate. The differences among means were tested by the StudentNewman-Keuls test. Data were considered statistically significant when $P<0.05$.

\section{RESULTS AND DISCUSSION}

\section{EPS Production and Bacterial Growth Ability}

The growth properties of bacteria and EPS yields of each strain were investigated and are shown in Table 1. Bifidobacterium bifidum WBIN03 produced the greatest amount of EPS $(241.20 \pm 1.55 \mathrm{mg} / \mathrm{L})$ compared with other Bifidobacterium in MRSc medium, and also possessed the best growth ability $\left(\mathrm{OD}_{600}\right.$ was $1.82 \pm 0.01$; Li et al., 2014). All the Lactobacillus strains and one Lactococcus strain used in this study produced EPS, and the amount of the EPS ranged from $45.49 \pm 12.46$ to $290.17 \pm 19.27 \mathrm{mg} / \mathrm{L}$. In addition, Lb. plantarum R315 produced much higher levels of EPS $(290.17 \pm 19.27$ $\mathrm{mg} / \mathrm{L}$ ) compared with other Lactobacillus strains. It also grew better in MRS (optical density at $600 \mathrm{~nm}$ was 1.85 $\pm 0.02)$ than other strains $(P<0.01)$. Based on these results, B. bifidum WBIN03 and Lb. plantarum R315 were selected for EPS extraction and further studies.

\section{Antioxidant Activity by Scavenging of DPPH Radicals}

The DPPH radical has been used as a tool to investigate the antioxidative activity of antioxidants (Zhang et al., 2013). In this study, the effect of EPS from $B$. bifidum WBIN03 (B-EPS) and EPS from $L b$. plantarum R315 (L-EPS) on DPPH scavenging ability is shown in Figure 1. The scavenging activity of 0.30 $\mathrm{mg} / \mathrm{mL}$ B-EPS $(60.08 \pm 3.01 \%)$ was similar to that of $0.25 \mathrm{mg} / \mathrm{mL}$ ascorbic acid $(62.78 \pm 2.19 \%)$ and higher than that of L-EPS $(56.48 \pm 3.10 \%)$ at the same concentration. In addition, scavenging activity increased with EPS concentration, and $0.50 \mathrm{mg} / \mathrm{mL}$ ascorbic acid $(96.16 \pm 0.74 \%)$ had activity similar to that $0.70 \mathrm{mg} /$ $\mathrm{mL}$ B-EPS $(94.40 \pm 2.15 \%)$ and $1.00 \mathrm{mg} / \mathrm{mL} \mathrm{L}-\mathrm{EPS}$ $(94.49 \pm 0.31 \%)$, respectively. These results indicate the strong antioxidative effect of these $2 \mathrm{EPS}$ on DPPH radical scavenging. 

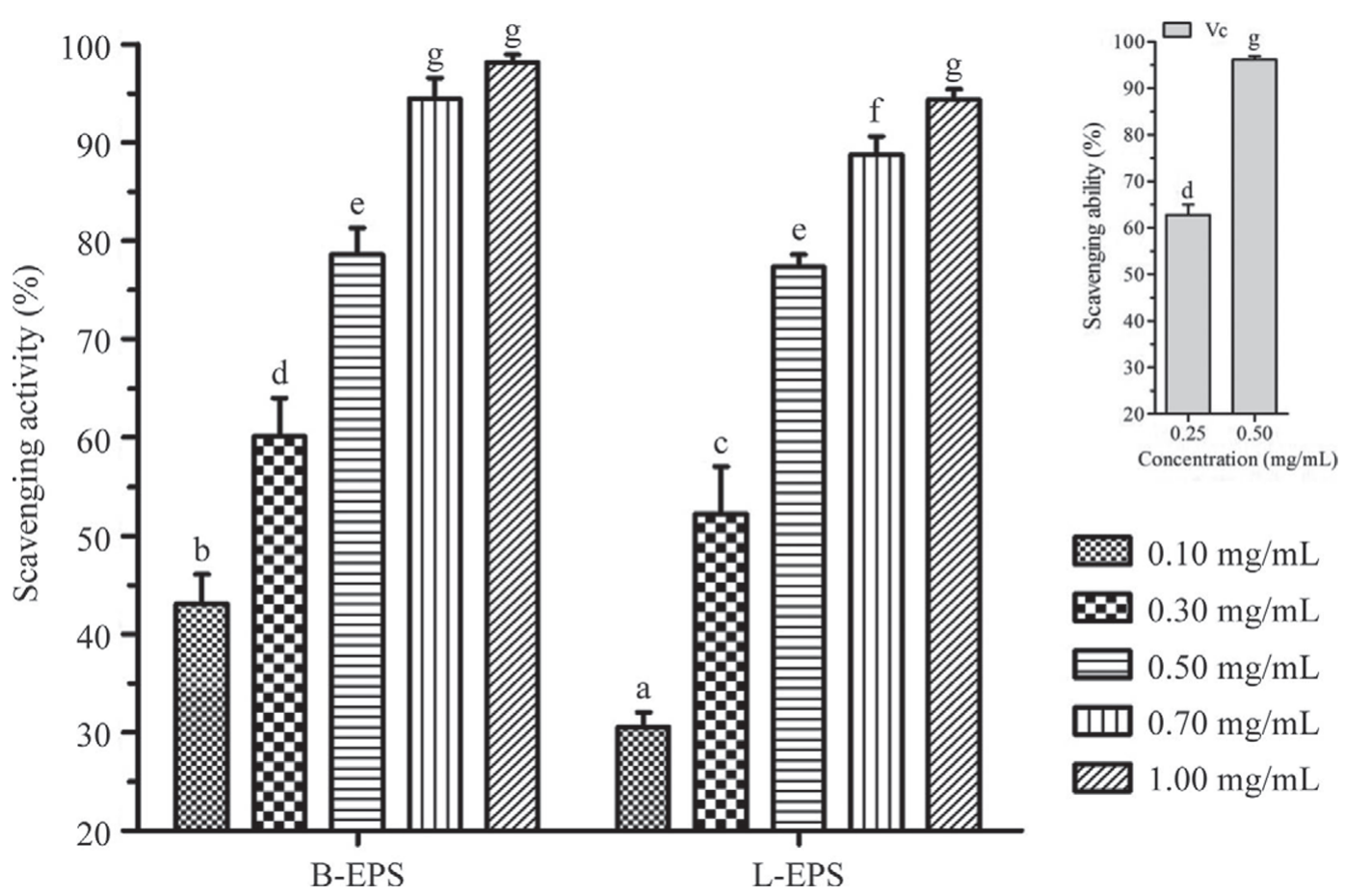

Figure 1. Scavenging effect of B-EPS and L-EPS on 1,1-diphenyl-2-picrylhydrazyl (DPPH) radicals compared with that of ascorbic acid. Data with different letters are significantly different at $P<0.05$. B-EPS $=$ EPS from Bifidobacterium bifidum WBIN03; L-EPS $=$ EPS from Lactobacillus plantarum $\mathrm{R} 315$; Vc = ascorbic acid.

\section{Antioxidant Activity by Scavenging of Hydroxyl Radicals}

Hydroxyl radical is a powerful oxidant that can react with almost all biological molecules (proteins, lipids and carbohydrates; Santanam et al., 1998). As shown in Figure 2, both B-EPS and L-EPS exhibited concentration-dependent scavenging activities against hydroxyl radicals, and scavenging activity increased with concentration in the range from 0.01 to $1.50 \mathrm{mg} /$ $\mathrm{mL}$. The scavenging ability of $0.10 \mathrm{mg} / \mathrm{mL}$ L-EPS $(39.15 \pm 0.58 \%)$ was similar to that of $0.25 \mathrm{mg} / \mathrm{mL}$ ascorbic acid $(36.48 \pm 2.44 \%)$ and was significantly higher than that of $0.15 \mathrm{mg} / \mathrm{mL}$ ascorbic acid $(24.33$ $\pm 1.17 \%)$ and B-EPS at all concentrations. In contrast, the scavenging ability of $1.50 \mathrm{mg} / \mathrm{mL}$ B-EPS $(31.91 \pm$ $1.62 \%)$ was only half that of L-EPS $(63.16 \pm 3.29 \%)$ at the same concentration, and was even lower than that of $0.25 \mathrm{mg} / \mathrm{mL}$ ascorbic acid $(36.48 \pm 2.44 \%)$. These results suggested that L-EPS had better hydroxyl radical scavenging activity than the reference ascorbic acid.

\section{Antioxidant Activity by Scavenging of Superoxide Radicals}

As free radical to cellular components, the superoxide radical is a precursor of more reactive oxidative species; for example, singlet oxygen and hydroxyl radical, and it can also initiate lipid peroxidation (Marklund and Marklund, 1974; Yin et al., 2010). The scavenging activity of B-EPS and L-EPS against superoxide radicals generated by 1,2,3-phetriol autoxidation is shown as Figure 3 . The scavenging activities of $0.10 \mathrm{mg} / \mathrm{mL}$ BEPS $(20.30 \pm 1.91 \%)$ and $0.10 \mathrm{mg} / \mathrm{mL} \mathrm{L-EPS}(25.25$ $\pm 2.63 \%$ ) were similar to that of $0.15 \mathrm{mg} / \mathrm{mL}$ ascorbic acid $(27.35 \pm 5.40 \%)$. However, at $1.00 \mathrm{mg} / \mathrm{mL}$, the scavenging activities of B-EPS $(59.75 \pm 8.12 \%)$ and L-EPS $(65.45 \pm 8.48 \%)$ were both slightly higher $(P>$ $0.05)$ than that of ascorbic acid at $0.25 \mathrm{mg} / \mathrm{mL}(57.38$ $\pm 4.86 \%)$. Thus, the superoxide scavenging abilities of B-EPS and L-EPS were similar.

\section{Inhibition of Lipid Peroxidation}

Lipid peroxidation is an oxidative deterioration process of PUFA induced by radicals (Su et al., 2009), and it is likely involved in numerous pathological events, including inflammation, metabolic disorder, and cellular aging (Wiseman and Halliwell, 1996). The inhibition of lipid peroxidation by B-EPS and L-EPS is shown in Figure 4. Both EPS exhibited dose-dependent inhibitory activities. At $0.50 \mathrm{mg} / \mathrm{mL}$, the inhibitory activities of B-EPS $(13.48 \pm 1.74 \%)$ and L-EPS $(12.43 \pm 0.51 \%)$ were similar but lower than that of ascorbic acid (23.20 $\pm 1.41 \%)$ at the same concentration; however, little difference was observed for a concentration range of 


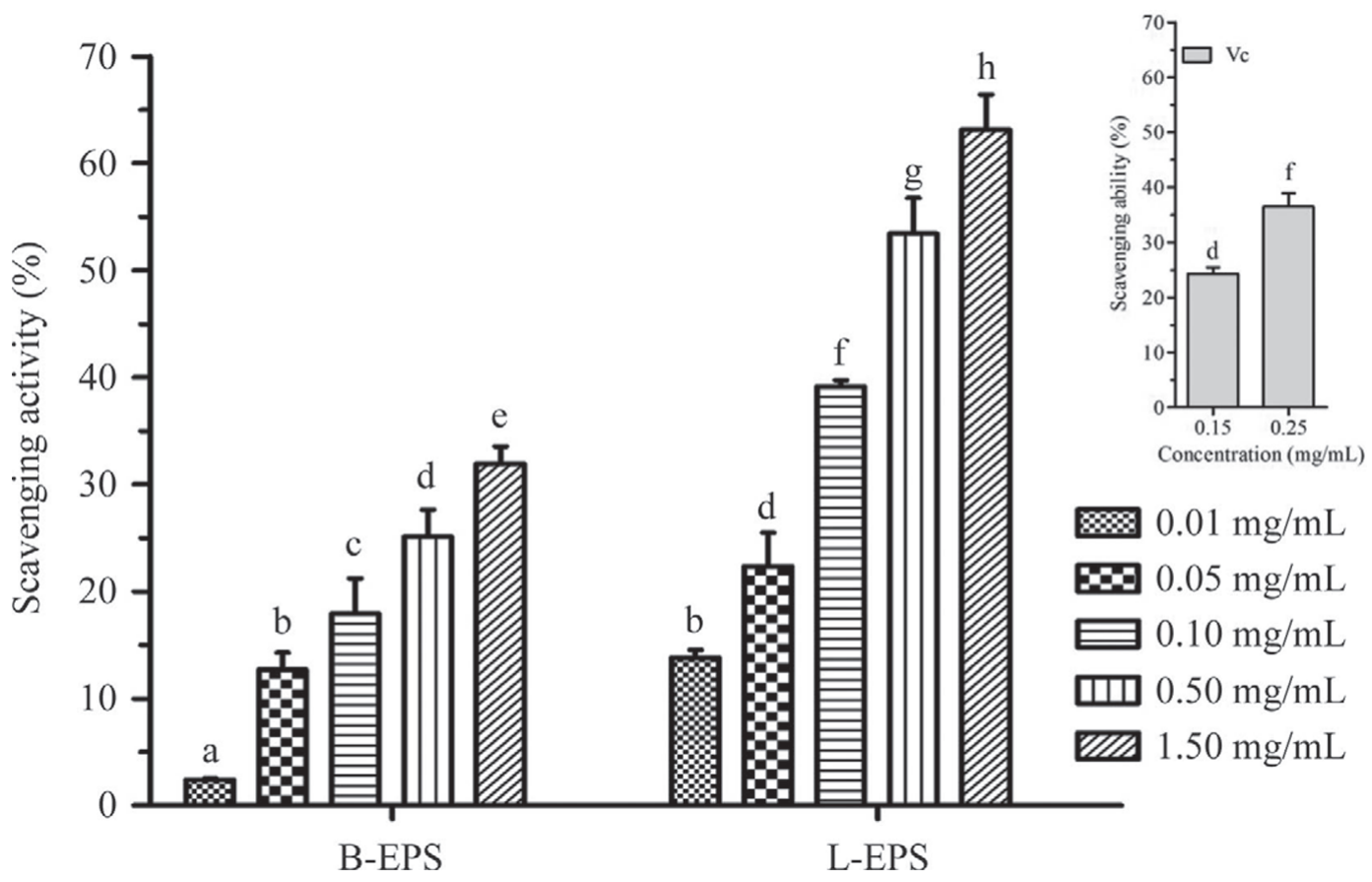

Figure 2. Scavenging effect of B-EPS and L-EPS on hydroxyl radicals compared with that of ascorbic acid. Data with different letters are significantly different at $P<0.05$. B-EPS $=$ EPS from Bifidobacterium bifidum WBIN03; L-EPS = EPS from Lactobacillus plantarum R315; $\mathrm{Vc}=$ ascorbic acid.

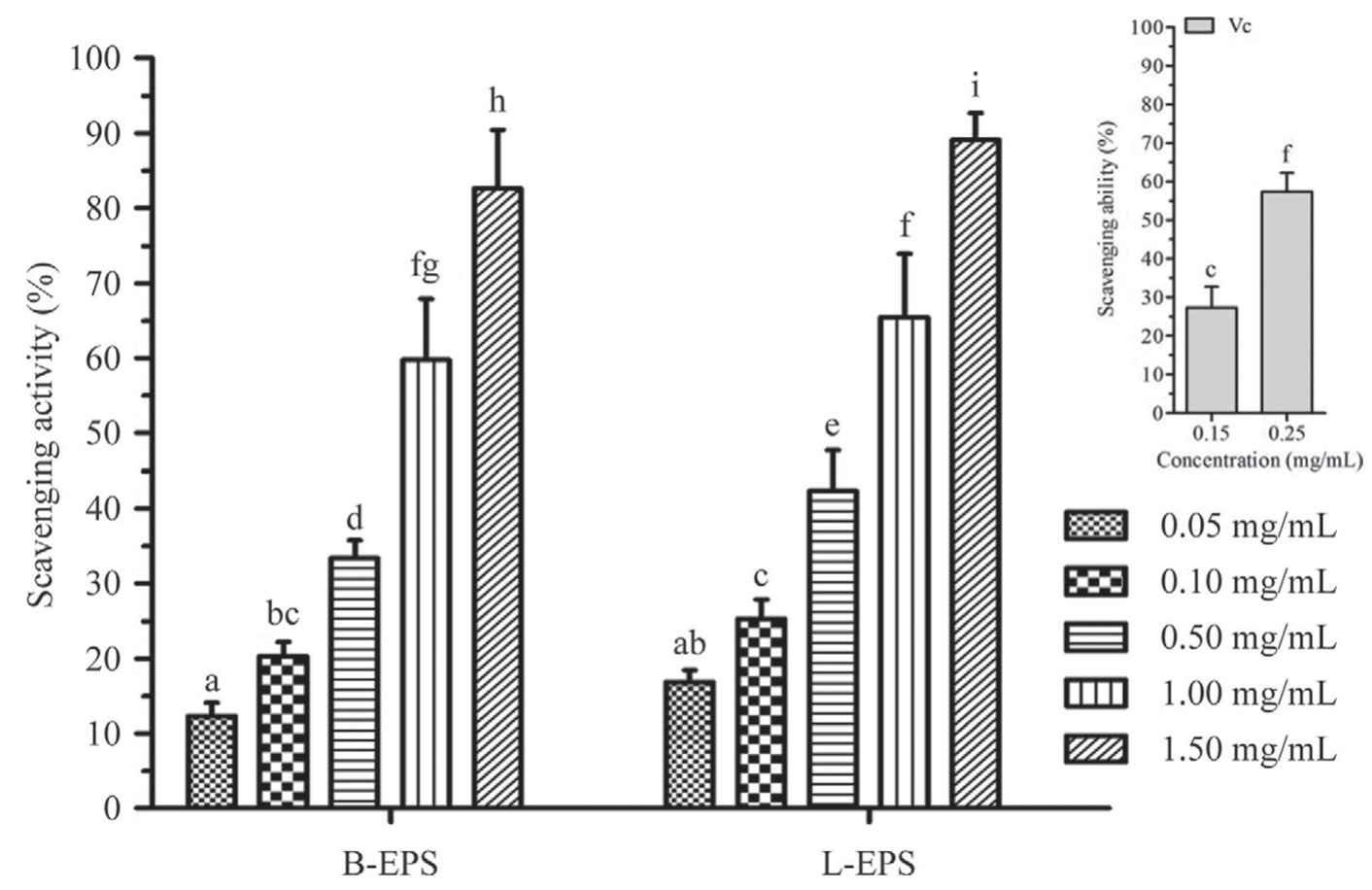

Figure 3. Scavenging effect of B-EPS and L-EPS on superoxide radicals generated by 1,2,3-phentriol autoxidation compared with that of ascorbic acid. Bars with different letters are significantly different at $P<0.05$; bars with common letters are not significantly different at $P>$ 0.05. B-EPS = EPS from Bifidobacterium bifidum WBIN03; L-EPS = EPS from Lactobacillus plantarum R315; Vc = ascorbic acid. 
1.00 to $1.50 \mathrm{mg} / \mathrm{mL}$, which indicated that they had similar inhibitory effect on lipid peroxidation. In the present work, $\mathrm{Fe}^{2+}$ induced the production of lipid radicals, and malondialdehyde (MDA) was quantified for determining the extent of lipid peroxidation. Several previous studies indicated that EPS from Lactobacillus and Bifidobacterium show strong inhibitory effects on lipid peroxidation (Shen et al., 2011; Xu et al., 2011a,b; Li et al., 2012; Guo et al., 2013); however, no details on the mechanism of action have been described.

\section{Inhibition of Mice Erythrocyte Hemolysis}

The oxidative hemolysis of erythrocytes from mice was used as the model to investigate the damage of biological membranes induced by free radicals and the protective effect of EPS. In the present study, we investigated the extent of hemolysis and inhibition rate of B-EPS and L-EPS on mice erythrocytes. As shown in Figure 5, the hemolysis rate for B-EPS, L-EPS, and ascorbic acid were $>90 \%$ at low concentrations $(0.10$ $0.30 \mathrm{mg} / \mathrm{mL})$ but decreased significantly $(P<0.5)$ at concentrations from 0.50 to $1.00 \mathrm{mg} / \mathrm{mL}$. The B-EPS had a stronger inhibitory effect on extent of hemolysis than did L-EPS or ascorbic acid (Figure 5A). Although the inhibition rate of ascorbic acid was $49.93 \pm 4.30 \%$ at $0.50 \mathrm{mg} / \mathrm{mL}$, B-EPS $(56.28 \pm 3.30 \%$ at $0.70 \mathrm{mg} / \mathrm{mL})$ and L-EPS $(42.73 \pm 3.15 \%$ at $1.00 \mathrm{mg} / \mathrm{mL})$ had similar inhibitory activities at higher concentration (Figure 5B). Several studies have demonstrated that some antioxidants from different materials; for example, natural products, cocoa, Nelumbo nucifera Gaertn., Mangifera indica L., exopolysaccharide from Bifidobacterium, show strong inhibitory effects on erythrocyte hemolysis induced by free radicals in vitro (Ng et al., 2000; Zhu et al., 2002; Saengkhae et al., 2007; Ajila and Prasada Rao, 2008; Xu et al., 2011b). Our results also suggested that EPS from $L b$. plantarum and B. bifidum could protect normal mice erythrocytes against damage in vitro in a dose-dependent manner.

\section{Antimicrobial Activity}

Antibacterial activity of B-EPS and L-EPS in samples is shown in Figure 6. Both B-EPS and L-EPS had equal antimicrobial activities against Listeria monocytogenes CMCC54007, Staph. aureus CGMCC26003, Bacillus cereus ATCC14579, and S. typhimurium ATCC13311, and the inhibition zones were lower than those with $50 \mu \mathrm{g} / \mathrm{mL}$ ampicillin. For Cronobacter sakazakii ATCC29544 and Shigella sonnei ATCC25931, the inhibition zones of L-EPS were $17.83 \pm 1.04$ and $10.67 \pm$ $0.29 \mathrm{~mm}$, respectively, which were significantly greater than those for B-EPS. In contrast, the inhibition zone

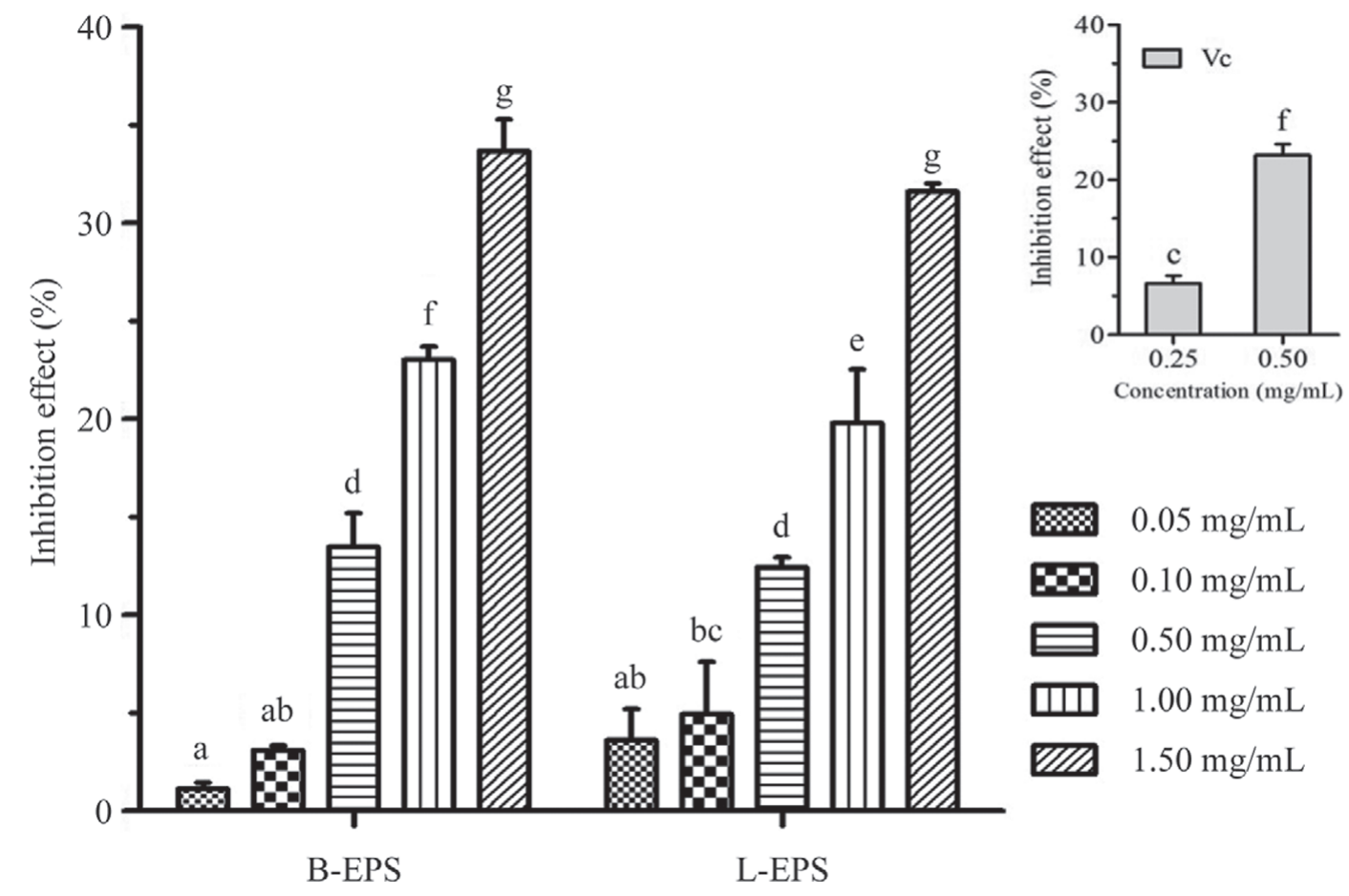

Figure 4. Inhibition of lipid peroxidation by B-EPS and L-EPS compared with that of ascorbic acid. Bars with different letters are significantly different at $P<0.05$; bars with common letters are not significantly different at $P>0.05$. B-EPS $=$ EPS from Bifidobacterium bifidum WBIN03; L-EPS = EPS from Lactobacillus plantarum R315; Vc = ascorbic acid. 

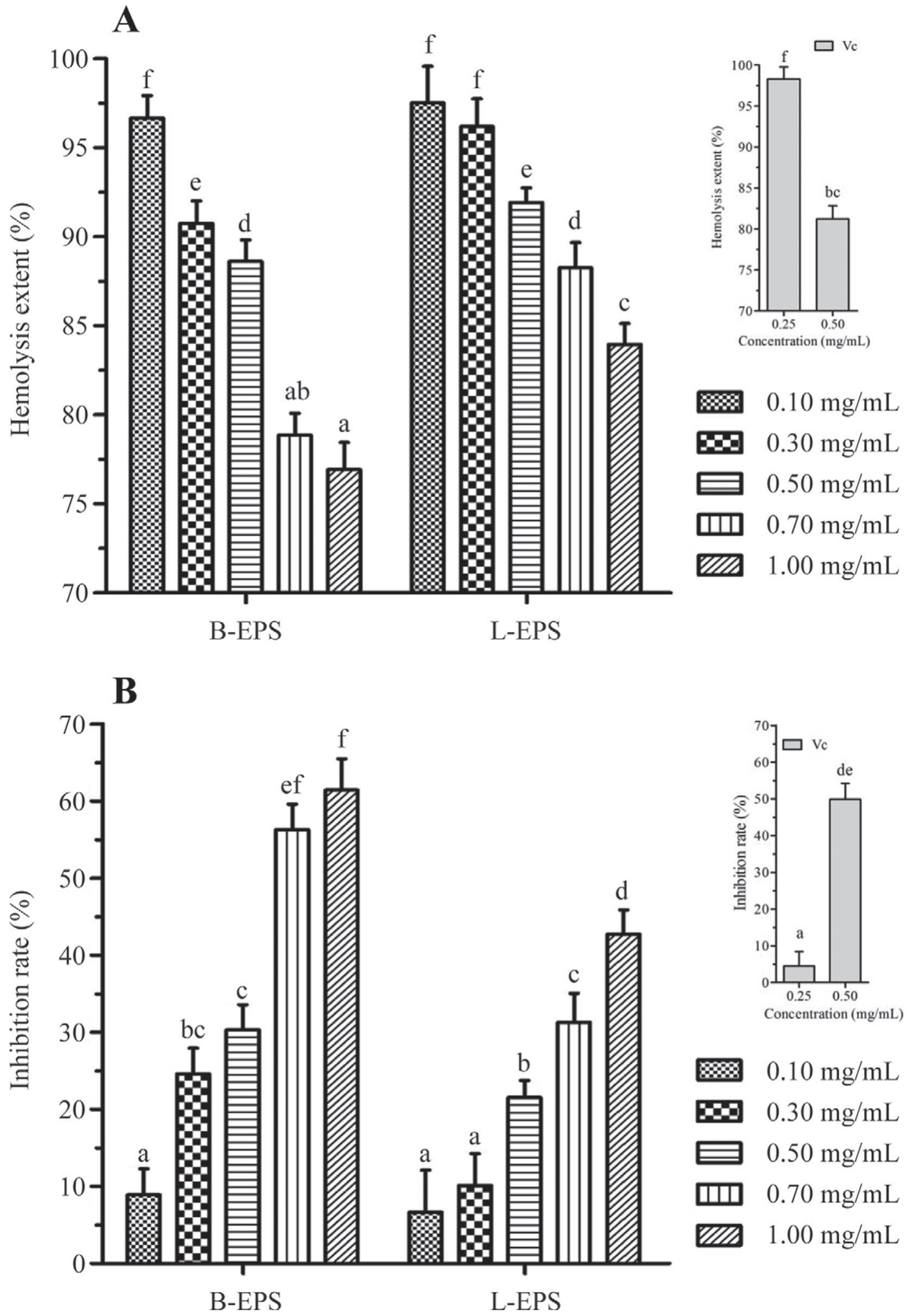

Figure 5. Effects of B-EPS and L-EPS on hemolysis of rat erythrocytes induced by $\mathrm{H}_{2} \mathrm{O}_{2}$ compared with that of ascorbic acid: (A) extent of hemolysis; (B) inhibition rate. Bars with different letters are significantly different at $P<0.05$; bars with common letters are not significantly different at $P>0.05$. B-EPS $=$ EPS from Bifidobacterium bifidum WBIN03; L-EPS $=$ EPS from Lactobacillus plantarum R315; Vc $=$ ascorbic acid. 


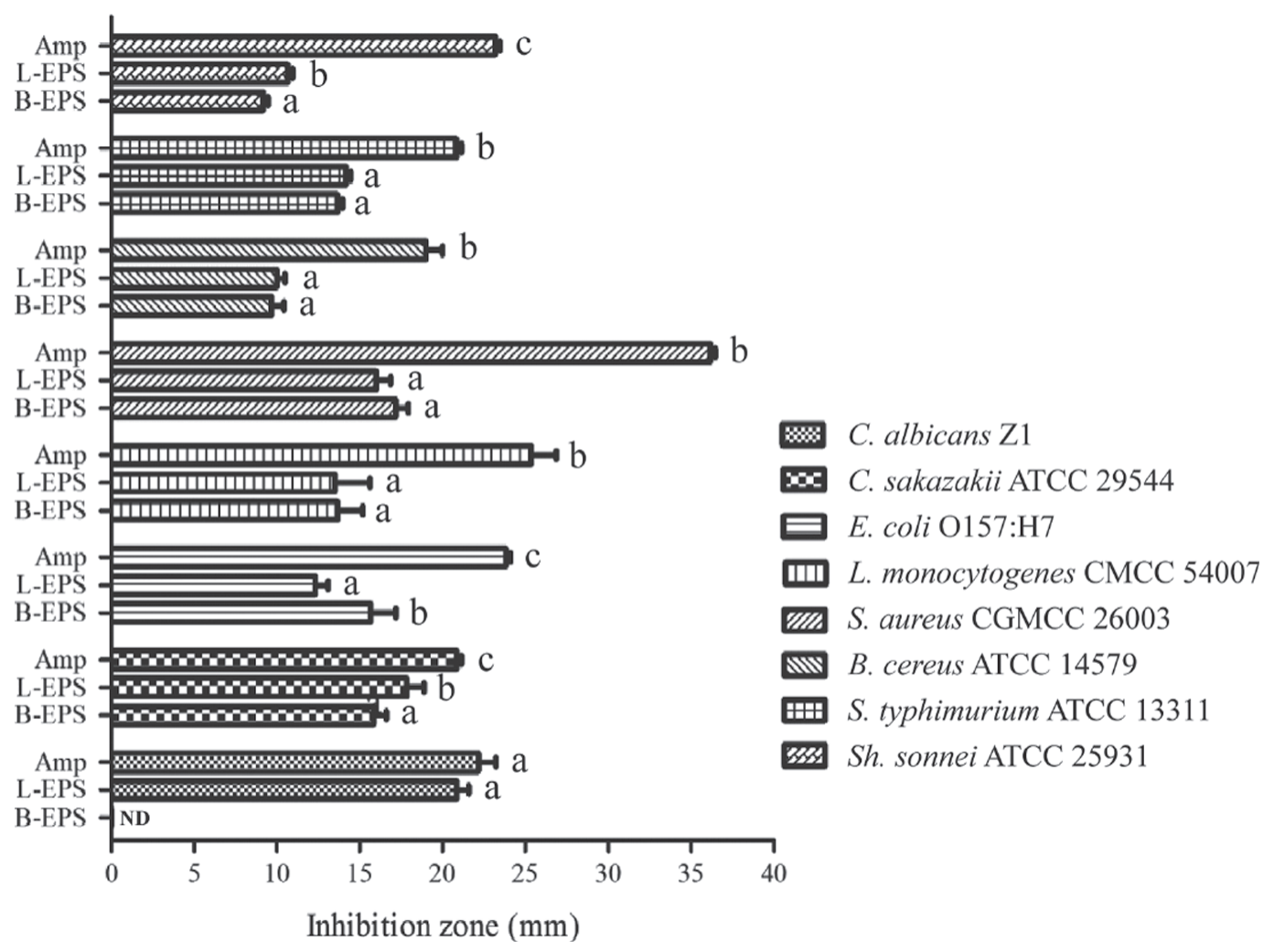

Figure 6. Antibacterial activities of B-EPS $(300 \mu \mathrm{g} / \mathrm{mL})$ and L-EPS $(300 \mu \mathrm{g} / \mathrm{mL})$ compared with that of ampicillin $(100 \mu \mathrm{g} / \mathrm{mL})$. Data with different letters are significantly different at $P<0.05 ; \mathrm{ND}=$ not detectable. B-EPS $=$ EPS from Bifidobacterium bifidum WBIN03; L-EPS $=$ EPS from Lactobacillus plantarum R315; Amp = ampicillin. Activity was monitored against Candida albicans, Cronobacter sakazakii, Escherichia coli, Listeria monocytogenes, Staphylococcus aureus, Bacillus cereus, Salmonella typhimurium, and Shigella sonnei.

of B-EPS for E. coli O157:H7 (15.67 $\pm 1.53 \mathrm{~mm})$ was significantly greater than that of L-EPS $(12.00 \pm 1.32$ $\mathrm{mm})$. Interestingly, L-EPS inhibited the growth of $C a$. albicans Z1 (20.83 $\pm 0.76 \mathrm{~mm})$ similarly to ampicillin; however, B-EPS had no effect on Ca. albicans Z1. A few studies showed that EPS from microorganisms had strong antimicrobial activity against several pathogens in vitro and have proposed several possible antibacterial mechanisms of EPS, such as impairing cell division, disrupting the cell wall and cytoplasmic membrane, and decomposing DNA (He et al., 2010; Wu et al., 2010). Although those studies did not describe the exact antagonistic mechanism of polysaccharide, protocols from these studies might lead to new areas in which to explore the antibacterial activity of polysaccharides.

\section{CONCLUSIONS}

In this study, all probiotic organisms studied could produce EPS under laboratory conditions, and B. bifidum WBIN03 and $L b$. plantarum R315 were able to produce EPS more effectively and exhibited better growth ability in the medium compared with the other strains. The results showed that both B-EPS and L-EPS had strong antibacterial ability against the tested pathogens. Similarly, they showed strong scavenging activity against DPPH, hydroxyl, and superoxide radicals, and inhibitory effects on lipid peroxidation and erythrocyte hemolysis. Although both EPS showed novel biological activities, further studies are needed to evaluate their structure and the components responsible for antimicrobial activity and mode of actions of EPS.

\section{ACKNOWLEDGMENTS}

This project was sponsored by the National Natural Science Foundation of China (NSF31170091, 31360377, 31260363), the Ganpo Talent Engineering 555 Project, the Academic and Technical Leaders Training Program for Major Subjects of Jiangxi Province (P. R. China), and the Research Program of the State Key Laboratory of Food Science and Technology of Nanchang University (SKLF-TS-200916, SKLF-ZZA-201302; Nanchang, P. R. China).

\section{REFERENCES}

Ajila, C. M., and U. Prasada Rao. 2008. Protection against hydrogen peroxide induced oxidative damage in rat erythrocytes by Mangifera indica L. peel extract. Food Chem. Toxicol. 46:303-309. 
Ames, B. N., M. K. Shigenaga, and T. M. Hagen. 1993. Oxidants, antioxidants, and the degenerative diseases of aging. Proc. Natl. Acad. Sci. USA 90:7915-7922.

Aruoma, O. I. 1998. Free radicals, oxidative stress, and antioxidants in human health and disease. J. Am. Oil Chem. Soc. 75:199-212.

Badel, S., T. Bernardi, and P. Michaud. 2011. New perspectives for lactobacilli exopolysaccharides. Biotechnol. Adv. 29:54-66.

Chen, T., Q. Tan, M. Wang, S. Xiong, S. Jiang, Q. Wu, S. Li, C. Luo, and H. Wei. 2011. Identification of bacterial strains in viili by molecular taxonomy and their synergistic effects on milk curd and exopolysaccharides production. Afr. J. Biotechnol. 10:1696916975.

Chen, T., Q. Wu, S. Li, S. Xiong, S. Jiang, Q. Tan, Z. Zhang, D. Zhu, and H. Wei. 2014. Microbiological quality and characteristics of probiotic products in China. J. Sci. Food Agric. 94:131-138.

Dubois, M., K. A. Gilles, J. K. Hamilton, P. Rebers, and F. Smith. 1956. Colorimetric method for determination of sugars and related substances. Anal. Chem. 28:350-356.

Gram, L., L. Ravn, M. Rasch, J. B. Bruhn, A. B. Christensen, and M. Givskov. 2002. Food spoilage-Interactions between food spoilage bacteria. Int. J. Food Microbiol. 78:79-97.

Guo, Y., D. Pan, H. Li, and B. Yan. 2013. Antioxidant and immunomodulatory activity of selenium exopolysaccharide produced by Lactococcus lactis ssp. lactis. Food Chem. 138:84-89.

He, F., Y. Yang, G. Yang, and L. Yu. 2010. Studies on antibacterial activity and antibacterial mechanism of a novel polysaccharide from Streptomyces virginia H03. Food Contr. 21:1257-1262.

Hidalgo-Cantabrana, C., P. López, M. Gueimonde, G. Clara, A. Suárez, A. Margolles, and P. Ruas-Madiedo. 2012. Immune modulation capability of exopolysaccharides synthesised by lactic acid bacteria and bifidobacteria. Probiotics Antimicrob. Prot. 4:227-237.

Kogan, G., M. Pajtinka, M. Babincova, E. Miadokova, P. Rauko, D. Slamenova, and T. Korolenko. 2008. Yeast cell wall polysaccharides as antioxidants and antimutagens: Can they fight cancer? Minireview. Neoplasma 55:387-393.

Li, J. Y., M. Jin, J. Meng, S. Gao, and R. Lu. 2013. Exopolysaccharide from Lactobacillus plantarum LP6: Antioxidation and the effect on oxidative stress. Carbohydr. Polym. 98:1147-1152.

Li, S., T. Chen, F. Xu, S. Dong, H. Xu, and H. Wei. 2014. The beneficial effect of the exopolysaccharides from Bifidobacterium bifidum WBIN03 on the microbial diversity in the mice intestine. J. Sci. Food Agric. 94:256-264.

Li, S., Y. Zhao, L. Zhang, X. Zhang, L. Huang, D. Li, C. Niu, Z. Yang, and Q. Wang. 2012. Antioxidant activity of Lactobacillus plantarum strains isolated from traditional Chinese fermented foods. Food Chem. 135:1914-1919.

Marklund, S., and G. Marklund. 1974. Involvement of the superoxide anion radical in the autoxidation of pyrogallol and a convenient assay for superoxide dismutase. Eur. J. Biochem. 47:469-474.

Nes, I. F., M. Kjos, and D. B. Diep. 2011. Antimicrobial components of lactic acid bacteria. Pages 285-329 in Lactic Acid Bacteria: Microbiological and Functional Aspects. 4th ed. CRC Press, Boca Raton, FL.

Ng, T. B., F. Liu, and Z. Wang. 2000. Antioxidative activity of natural products from plants. Life Sci. 66:709-723.

Ruas-Madiedo, P., J. Hugenholtz, and P. Zoon. 2002. An overview of the functionality of exopolysaccharides produced by lactic acid bacteria. Int. Dairy J. 12:163-171.

Saengkhae, C., W. Arunnopparat, and P. Sungkhajorn. 2007. Antioxidative activity of the leaf of Nelumbo nucifera Gaertn. on oxidative stress-induced erythrocyte hemolysis in hypertensive and normotensive rats. Thai J Physiol Sci. 20:70-78.

Santanam, N., S. Ramachandran, and S. Parthasarathy. 1998. Oxygen radicals, antioxidants, and lipid peroxidation. Semin. Reprod. Endocrinol. 16:275-280.
Sayre, L. M., M. A. Smith, and G. Perry. 2001. Chemistry and biochemistry of oxidative stress in neurodegenerative disease. Curr. Med. Chem. 8:721-738. .

Serafini, F., F. Strati, P. Ruas-Madiedo, F. Turroni, E. Foroni, S. Duranti, F. Milano, A. Perotti, A. Viappiani, and S. Guglielmetti. 2013. Evaluation of adhesion properties and antibacterial activities of the infant gut commensal Bifidobacterium bifidum PRL2010. Anaerobe 21:9-17.

Shen, Q., N. Shang, and P. Li. 2011. In vitro and in vivo antioxidant activity of Bifidobacterium animalis 01 isolated from centenarians. Curr. Microbiol. 62:1097-1103.

Sokmen, A., M. Gulluce, H. Askin Akpulat, D. Daferera, B. Tepe, M. Polissiou, M. Sokmen, and F. Sahin. 2004. The in vitro antimicrobial and antioxidant activities of the essential oils and methanol extracts of endemic Thymus spathulifolius. Food Contr. 15:627634

Soubra, L., D. Sarkis, C. Hilan, and Ph. Verger. 2007. Dietary exposure of children and teenagers to benzoates, sulphites, butylhydroxyanisol (BHA) and butylhydroxytoluen (BHT) in Beirut (Lebanon). Regul. Toxicol. Pharmacol. 47:68-77.

$\mathrm{Su}$, X., Z. Wang, and J. Liu. 2009. In vitro and in vivo antioxidant activity of Pinus koraiensis seed extract containing phenolic compounds. Food Chem. 117:681-686.

Valentão, P., E. Fernandes, F. Carvalho, P. B. Andrade, R. M. Seabra, and M. L. Bastos. 2002. Antioxidative properties of cardoon $(C y-$ nara cardunculus L.) infusion against superoxide radical, hydroxyl radical, and hypochlorous acid. J. Agric. Food Chem. 50:49894993.

Wiseman, H., and B. Halliwell. 1996. Damage to DNA by reactive oxygen and nitrogen species: role in inflammatory disease and progression to cancer. Biochem. J. 313:17-29.

Wu, M. H., T. Pan, Y. Wu, S. Chang, M. Chang, and C. Hu. 2010. Exopolysaccharide activities from probiotic bifidobacterium: Immunomodulatory effects (on J774A.1 macrophages) and antimicrobial properties. Int. J. Food Microbiol. 144:104-110.

Xu, R., N. Shang, and P. Li. 2011a. In vitro and in vivo antioxidant activity of exopolysaccharide fractions from Bifidobacterium animalis RH. Anaerobe 17:226-231.

Xu, R., Q. Shen, X. Ding, W. Gao, and P. Li. 2011b. Chemical characterization and antioxidant activity of an exopolysaccharide fraction isolated from Bifidobacterium animalis RH. Eur. Food Res. Technol. 232:231-240.

Yin, J. Y., S. P. Nie, C. Zhou, Y. Wan, and M. Y. Xie. 2010. Chemical characteristics and antioxidant activities of polysaccharide purified from the seeds of Plantago asiatica L. J. Sci. Food Agric. 90:210-217.

Ye, Y., H. Li, Q. Wu, J. Zhang, and Y. Lu. 2014. The Cronobacter sp. in milk and dairy products: Detection and typing. Int. J. Dairy Technol. 67:167-175. http://dx.doi.org/10.1111/1471-0307.12111.

Zhang, L., C. Liu, D. Li, Y. Zhao, X. Zhang, X. Zeng, Z. Yang, and S. Li. 2013. Antioxidant activity of an exopolysaccharide isolated from Lactobacillus plantarum C88. Int. J. Biol. Macromol. $54: 270-275$.

Zhang, S., L. Liu, Y. Su, H. Li, Q. Sun, X. Liang, and J. Lv. 2011. Antioxidative activity of lactic acid bacteria in yogurt. Afr. J. Microbiol. Res. 5:5194-5201.

Zhu, Q. Y., R. R. Holt, S. A. Lazarus, T. J. Orozco, and C. L. Keen. 2002. Inhibitory effects of cocoa flavanols and procyanidin oligomers on free radical-induced erythrocyte hemolysis. Exp. Biol. Med. (Maywood) 227:321-329. 